\title{
Kermes Meşesi [Quercus coccifera (L.)] Yaprak Ekstraktının Tetranychus urticae Koch, Callosobruchus maculatus F. ve Plodia interpunctella (Hubner)'ya Toksik Etkileri
}

\author{
Hüseyin ÇETIN 1 Fatma Nur ELMA ${ }^{2}$ - \\ Selçuk Üniversitesi Ziraat Fakültesi Bitki Koruma Bölümü Kampüs/Konya \\ ${ }^{1}$ https://orcid.org/0000-0002-3252-0778, ${ }^{2}$ https://orcid.org/0000-0003-0985-0338 \\ 凶:fdundar@selcuk.edu.tr
}

\section{ÖZET}

Bu çalışmada, Kermes meşesi, Quercus coccifera (L.) yapraklarından elde edilen ekstraktın kültür bitkilerinin önemli zararlılarından Pamuk kırmızıörümceği, Tetranychus urticae Koch (Acarina: Tetranychidae), depolanmış ürün zararlılarından Börülce tohumböceği, Callosobruchus maculatus F. (Coleoptera: Chrysomelidae) ve Kuru meyve güvesi, Plodia interpunctella (Hubner) (Lepidoptera: Pyralidae)'ya toksik etkileri araştırılmıştır. T. urticae ve $C$. maculatus'un erginleri, $P$. interpunctellanın ise 3- 4. dönem larvaları denemelerde kullanılmıştır. Yaprak ekstraktının (\% $20, \% 10, \% 5, \% 2.5$ ve $\% 1.25(\mathrm{w} / \mathrm{w}))$ beş farkl konsantrasyonu kullanılmıştır. Denemeler $28 \pm 1^{\circ} \mathrm{C}$ sıcaklık, \% $65 \pm 5$ orantılı nem $(T$. urticae için 16 saat aydınlatma süresi) koşullarında yürütülmüştür. Denemeler 3 tekerrürlü olarak yürütülmüş̧ür. Sayımlar uygulamadan 24 ve 48 saat sonra yapılmış ve ölü ve canlı bireyler kaydedilmiştir. T. urticae' de bitki ekstraktının oldukça etkili olduğu ve uygulamadan 48 saat sonra \% 10'lik konsantrasyonda \% 98 oranında ölüm meydana getirdiği görülmüştür. C. maculatus'ta en yüksek ölüm oranı \% 20'lik ekstrakt konsantrasyonunda ve 48 saat sonunda \% 96 olarak belirlenmiştir. $Q$. coccifera yaprak ekstraktının $P$. interpunctella larvalarına toksik etkisinin düşük olduğu belirlenmiştir.

\section{Araştırma Makalesi}

\author{
Makale Tarihçesi \\ Geliş Tarihi $\quad: 26.10 .2018$ \\ Kabul Tarihi : 03.12 .2018
}

Anahtar Kelimeler

Callosobruchus maculatus

Quercus coccifera

Plodia interpunctella

Tetranychus urticae

Toksik etki

Toxic Effects of Quercus coccifera (L.) Leaf Extract on Tetranychus urticae Koch, Callosobruchus maculatus F. and Plodia interpunctella (Hubner)

\section{ABSTRACT}

In this study, toxicities of the leaf extract of Quercus coccifera (L.) were tested against Tetranychus urticae Koch (Acarina: Tetranychidae), Callosobruchus maculatus F. (Coleoptera: Chrysomelidae) and Plodia interpunctella (Hubner) (Lepidoptera: Pyralidae). The adults of the T. urticae and C. maculatus and the $3^{-}$ 4th instars larvae of the $P$. interpunctella were used in the experiment. Plant extracts were used at the five different concentrations $(20 \%, 10 \%, 5 \%, 2.5 \%, 1.25 \%(\mathrm{w} / \mathrm{w}))$. The studies were conducted under the laboratory conditions with $28 \pm 1{ }^{\circ} \mathrm{C}, 65 \pm 5 \%$ relative humidity (16:8 L/D time period for $T$. urticae). Trials were replicated for three time. Mortality was recorded for 24 and 48 hours post-treatment. $Q$. coccifera extract was found to be quietly effective against T. urticae adults with a $98 \%$ mortality rate in 48 hours and at $10 \%$ concentrations. The highest death rate $(96 \%)$ of $C$. maculatus adults was determined after 48 hours of post treatment and at $20 \%$ concentration. Toxic effect of $Q$. coccifera leaf extract to $P$. interpunctella larvae was determined to be low.

\section{Research Article}

Article History

Received

: 26.10.2018

Accepted : :03.12.2018

\section{Keywords}

Callosobruchus maculatus

Quercus coccifera

Plodia interpunctella

Tetranychus urticae

Toxic effect

To Cite : Çetin H, Elma FN 2019. Kermes Meşesi [Quercus coccifera (L.)] Yaprak Ekstraktının Tetranychus urticae Koch, Callosobruchus maculatus F. ve Plodia interpunctella (Hubner)'ya Toksik Etkileri. KSÜ Tarim ve Doğa Derg 22(2) 224-229. DOI: 10.18016/ksutarimdoga.vi.475042 


\section{GİṘŞ}

Zararlılar, sera ve açık alanlarda yetiştiriciliği yapılan kültür bitkilerinin gelişmesini olumsuz yönde etkili olmakta, aynı şekilde depolanmış ürünlerde de büyük kayıplara neden olmaktadırlar (Öncüer, 2000; Yanar ve Düzdemir, 2012). Tetranychus urticae Koch (Acarina: Tetranychidae) tarla ve serada yetiştirilen bitkilerde önemli bir polifag zararlıdır. Bu akar türü, Türkiye'nin Akdeniz Bölgesi'nde, fasulye, salatalık, patlıcan ve biber gibi sera bitkilerinin yanı sıra çilek ve pamuk gibi birçok bitkinin zararlısıdır (Bulut ve Göçmen, 2000; Dağlı ve Tunç, 2001). Sicak ve kuru koşullarda yumurtadan ergine yaklaşık bir hafta içinde ulaşmakta ve yılda çok sayıda döl vermektedir.

Börülce tohumböceği Callosobruchus maculatus (F.), özellikle baklagillerin önemli bir zararlısıdır. Türkiye'de konukçusunun bulunduğu tüm bölgelerde yayılım göstermekte ve serin iklim bölgelerinde yalnızca depoda yaşamını sürdürebilmektedir. Uygun koşullarda sürekli döl verebilmesi ve ergin diyapozunun olmaması, tarladan depoya depodan da tarlaya bulaşabilmesiyle oldukça önemli zararlar meydana getirebilmektedir. Bu özellikleri zararlıya karşı mücadelenin önemini artırmaktadır.

Kuru meyve güvesi Plodia interpunctella (L.) (Lepidoptera: Pyralidae) kurutulmuş meyveler başta olmak üzere tahıl ve tahıl ürünleri, süt tozu, mısır unu, buğday unu, kuru biber gibi çeşitli işlenmiş ve işlenmemiş ürünlerde sıklıkla karşılaşılan bir zararlıdır (Johnson ve ark. 1992; Nansen ve ark. 2004). Larvalar, beslenme zararının yanı sıra, yiyecekler üzerinde göze hoş görünmeyen ipeğimsi ağ örüntüsü, deri atıkları ve dışkılarını bırakmak vasıtasıyla ürünü kirleterekte zarar meydana getirmektedir.

Bitkilerin yaprak, çiçek, kabuk ve bunun gibi farklı kısımlarından değişik yöntemlerle elde edilen ekstraktların, insektisitler için önemli potansiyel kaynaklar olduğu birçok araştırıcı tarafindan ispatlanmıştır. (Gökçe ve ark. 2007; Kamaraj ve ark., 2008; Çetin ve Elma, 2017; Karakaş, 2017; Shiberu ve Getu, 2017; Louise ve ark., 2018). Türkiye'nin Doğu Akdeniz Bölgesi, yerli aromatik ve şifalı bitki türleriyle zengin bir floraya sahiptir (Avc1, 2005). Quercus coccifera L., Fagaceae familyasından, makilik alanlarda boy gösteren herdem yeşil bir bitkidir. Özellikle Akdeniz florasında vadiler aracılığı ile hem yatay yönde ve hem de dikey yönde çok geniş alanlarda yayılış göstermektedir (Yaşar ve ark, 2017).

Tarimsal alanlara uygulanan pestisitler; hava, su ve toprağa, oradan da bu ortamlarda yaşayan diğer canlılara geçmekte ve sonuçta kirliliğe ve toksik etkiye yol açmaktadır. Bugüne kadar yapılan toksikolojik araştırmalarda pesitisitlerin deri, ağız ve solunum yoluyla girerek insanlarda zehirlenmelere sebep olduğu saptanmıştır. Yine, zehirlenmeler pestisitlerin kazara veya uygulama sirasinda doğrudan doğruya alınması sonucu doza bağlı olarak akut (ani) veya kronik zehirlenmeler şeklinde de görülebilir. Pesitisitlerin insanlara verdiği zararlı etki dışında, pestisitler ayrıca zararlı etmenleri doğada baskı altında tutan faktörlerden en önemlisi olan parazitoit ve predatörlere de etki etmektedir. Ayrıca bal arıları, yaban hayat ve evcil hayvanlar da pestisit kullanımından yoğun bir şekilde etkilenmektedir (Yıldırım, 2008). Türkiye'de tarım ilacı kullanımı giderek artmaktadır (Altıkat ve ark., 2009).

Bitkisel üretimdeki öncelikler arasında "sağlıklı ürün" yani zararlı kimyasallarla bulaşmamış ürün anlayışı önemli bir yer tutmaktadır. Son yıllarda, sivil toplum örgütlerinin ve tüketicilerin baskılarıyla, pestisitlerin çevreye ve sağlı̆̆a daha az zarar verecek biçimde kullanılması giderek önem kazanmış ve gıda güvenliği sorunlarının çözümünde; ekonomik açıdan karlı, sosyal açıdan yaşanabilir, çevreye zarar vermeyen ve sürdürülebilir kalkınmayı sağlayan politikalar geliştirilmeye başlanmıştır (Tiryaki ve ark., 2012). Mevcut geleneksel pestisitlere karşı dayanıklılığın gelişmesi, artan çevre kirliliği ve yarattığı sağlık sorunları nedeniyle bunlarin alternatiflerinin bulunması son yıllarda bitki koruma alanında çalışanların araştırdıkları bir konu haline gelmiştir. Bu açıdan zararlı böceklerin kontrolü için halihazırda kullanılan insektisitlere bir alternatif olarak bitkisel kökenli insektisitler önemli bir yer tutmaktadır. Ülkemiz, bu zengin bitki varlığ kökenli insektisitlerin bulunabileceği önemli alanlardan biridir. Bu çalışmada Quercus coccifera yapraklarindan elde edilen methanol ekstraktının Tetranychus urticae ve Callosobruchus maculatus erginlerine, Plodia interpunctella'nın larvalarına toksik etkileri araştırılmıştır.

\section{MATERYAL ve YÖNTEM}

\section{Materyal}

\section{Bitki Ekstraksiyonu}

Mersin'in Mut ilçesinde 204 metre rakımdaki zeytin bahçeleri içerisinde bulunan Kermes Meşesi'nin hasatı Temmuz 2015'de yapraklı dönemde toprak yüzeyinden tüm bitki şeklinde kesilerek yapılmıştır. Bitkinin yaprakları laboratuvarda gölge ve havadar ortamda 67 gün kurutulmuştur. Daha sonra kurutulmuş bitki materyali değirmen vasıtasıyla öğütülmüş ve 50 gram olacak şekilde cam kavanoza alınmıştır. Üzerine 500 $\mathrm{ml}$ methanol ilave edilerek ağız kısmı alüminyum folyo ile kapatılan kavanozlar karanlık bir ortamda oda sicaklığında 5-6 gün ara ara çalkalanarak bekletilmiştir. $\mathrm{Bu}$ sürenin sonunda bitki süspansiyonları filtre kağıdından süzülerek sıvı kısmı alınıp posası atılmıştır. Elde edilen süzütler Rotari evaporatör cihazı yardımıyla $40 \pm 2^{\circ} \mathrm{C}$ sıcaklıkta methanolün uçması sağlanmış ve bitki ekstraktı elde edilmiştir (Tavares ve ark., 2009). Daha sonra saf su 
ile seyreltilip \% 20, \% 10, \% 5, \% 2.5 ve $\% 1.25(\mathrm{w} / \mathrm{w})^{\prime}$ lik olmak üzere beş konsantrasyonu hazırlanarak denemelerde kullanılmıştır. Kontrol olarak saf su kullanılmıştır.

\section{Böcek Kültürünün Yetiştirilmesi}

Callosobruchus maculatus ve Plodia interpunctella Selçuk Üniversitesi Ziraat Fakültesi Bitki Koruma Bölümü Entomoloji laboratuvarındaki $28 \pm 1^{\circ} \mathrm{C}$ sıcaklık, \% $55 \pm 5$ nemde ve tamamen karanlık koşullardaki iklim kabininde bulunan stok kültürden temin edilmiştir. C. maculatus un üretiminde besin olarak nohut, $P$. Interpunctella'da ise kuru üzüm kullanılmıştır. Tetranychus urticae ise yine Selçuk Üniversitesi Ziraat Fakültesi Bitki Koruma Bölümünde yetiştirilen stok kültüründen elde edilmiş ve $28 \pm 1^{\circ} \mathrm{C}$ sıcaklık, \% $65 \pm 5$ nem ve $16: 8$ işılanma periyodunda yetiştirilen fasülye (Phaseolus vulgaris) bitkisinin yaprakları üzerinde çoğaltılmıştır.

\section{Yöntem}

\section{Toksik Etki Çalışmaları}

Denemeler ve stok kültür yetiştirme faaliyetleri $28 \pm 1^{\circ} \mathrm{C}$ sıcaklık, $\% 65 \pm 5$ orantılı nem ( . urticae için 16 saat aydınlatma süresi) koşullarına sahip iklim kabininde yürütülmüştür. Denemelerde Callosobruchus maculatus un 1 günlük erginleri, Plodia interpunctella' nın ise 3-4. dönem larvaları kullanılmıştır. Hazırlanan ekstraktın her bir konsantrasyonu C. maculatus' un erginlerinin (erkek ve dişilerden rastgele seçilmiştir) ve $P$. interpunctella larvalarının thoraks dorsaline mikro aplikatör vasıtasıyla $2 \mu \mathrm{l} / \mathrm{böcek}$ olacak şekilde uygulanmıştır. Uygulamadan önce hareketin azalması için böcekler 2 ${ }^{\circ} \mathrm{C}$ 'de soğutmalı inkübatörde 10-15 dakika bekletilmiştir. Her konsantrasyon için 20 bireye uygulama yapılmış, petri kabına alınan bireyler iklim kabinine alınarak 24 ve 48 saat bekletildikten sonra ölü ve canlılar sayılmıştır. Ölü olanlara fırça ile dokunularak hareket olup olmadığı kontrol edilmiş, hareket görülenler canlı kabul edilmiştir. Denemeler 3 tekerrürlü olarak yürütülmüştür (Çetin ve Elma, 2017).

Tetranychus urticae erginleri için denemeler $3 \mathrm{~cm}$ çapında kesilen ve içerisinde ıslak pamuk katmanı bulunan petri kaplarina yerleştirilen fasulye yaprak diskleri üzerinde gerçekleştirilmiştir. Her yaprak diski ekstrakt çözeltisine batırıldıktan sonra alt yüzeyi üste gelecek şekilde kurutma kağıdı üzerinde yapraktaki ıslaklık kayboluncaya kadar bekletilmiştir (Erdoğan ve ark., 2010). Daha sonra yapraklar ıslatılmış pamuk bulunan petri kaplarına alt kısmında boşluk kalmayacak şekilde yerleştirilmiş ve her diske furça yardımıyla 20 akar yerleştirilmiştir. Her yaprak diski bir tekerrür olarak kabul edilmiş, denemeler üç tekerrürlü olarak yürütülmüştür. Sayımlar uygulamadan 24 ve 48 saat sonra yapılmış ve ölü ve canlı bireyler kaydedilmiştir. Elde edilen veriler Abbott formülü (Abbott, 1925) kullanılarak düzeltilmiş $\%$ ölüm değerleri belirlenmiştir.

(Düzeltilmiş \% Ölüm= ([(A-B)/A ] x 100 (A, kontroldeki $\%$ canll; B, muameledeki \% canlı)).

\section{BULGULAR ve TARTIŞMA}

Quercus coccifera Ekstraktının Callosobruchus maculatus Erginlerine Toksik Etkisi

Quercus coccifera Ekstraktınin Callosobruchus maculatus erginlerinde meydana getirdiği ölüm oranları Çizelge 1'de verilmiştir.

Çizelge 1. Quercus coccifera yaprak ekstraktının Callosobruchus maculatus erginlerine toksik etkisi

\begin{tabular}{ccc}
\hline \multirow{2}{*}{$\begin{array}{c}\text { Ekstrakt } \\
\text { konsantrasyonu } \\
(\% \text { w/w })\end{array}$} & \multicolumn{2}{c}{$\begin{array}{c}\text { Ergin Ölüm Oranı } \\
(\% \pm \text { standart hata) }\end{array}$} \\
\cline { 2 - 3 } & \multicolumn{2}{c}{ Maruz Bırakma Süresi } \\
\hline & 24 saat & 48 saat \\
\hline 1.25 & $81.18 \pm 1.45$ & $92.46 \pm 1.15$ \\
\hline 2.5 & $85.01 \pm 1.36$ & $93.33 \pm 2.56$ \\
\hline 5 & $86.03 \pm 2.20$ & $94.46 \pm 2.82$ \\
\hline 10 & $87.73 \pm 2.52$ & $94.99 \pm 2.86$ \\
\hline 20 & $90.74 \pm 1.48$ & $96.23 \pm 1.56$ \\
\hline Kontrol & $0.00 \pm 0.00$ & $0.00 \pm 0.00$ \\
\hline
\end{tabular}

Bitki ekstraktının beş konsantrasyonu (\% 20, \% 10, \% $5, \% 2.5$ ve $\% 1.25 \mathrm{w} / \mathrm{w})$ ve iki farklı maruz birakma süresinin (24 ve 48 s) C. maculatus'a etkisi değerlendirilmiştir $Q$. coccifera ekstraktının $C$. maculatus üzerindeki toksik etkisinin oldukça yüksek olduğu ve düşük konsantrasyonlarda bile (\% 1.25, 2.50) \%80'nin üzerinde ölüm meydana getirdiği tespit edilmiştir. 48 saat sonunda \% 20'lik dozda \% 96 ölüm meydana getirmiştir. Daha önce bazı araştırmacılar $C$. maculatus a karşı bazı bitki ekstraktlarının etkili olduğunu bildirmiştir. Taş ve ark. (2015), Kimyon Cuminum cyminum, Sar1 kantaron Hypericum perforatum, Anason Pimpinella anisum, Kekik Origanum onites bitkilerinin methanol ekstraktını test ettikleri çalışmada, Kimyon ekstraktının 48 saat sonunda \% 16'llk dozda $C$. maculatus ergininde \%98 oranında ölüme neden olduğunu bildirmişlerdir. Çetin ve Elma (2017), Tarçın Cinnamomum cassia (Blume), Defne Laurus nobilis L., Karanfil Syzygium aromaticum (L.) ve Biberiye Rosmarinus officinalis L. metanol ekstraktlarının kontakt etkilerini tespit etmek için yaptıkları çalışmada, 24 saat sonunda $L$. nobilis in $\mathrm{LC}_{50}$ değeri \% 2.02, S. aromaticum'un ise \% 3.78 olduğu tespit etmişlerdir. Bhaduri ve ark. (1985), Persicaria hydropiper bitkisinin yapraklarından elde edilen ekstraktların $C$. maculatus erginlerinde doz artışıyla birlikte yüksek derecede değme (kontak) etki gösterdiğini belirlemişlerdir. 
Quercus coccifera Ekstraktının Tetranychus urticae Erginlerine Toksik Etkisi

Quercus coccifera ekstraktının Tetranychus urticae erginlerinde her iki uygulama süresinde de \% 20'lik konsantrasyonda \% 100'lük ölüm meydana getirmiştir (Çizelge 2).

Çizelge 2. Quercus coccifera yaprak ekstraktının Tetranychus urticae erginlerine toksik etkileri

\begin{tabular}{ccc}
\hline \multirow{2}{*}{$\begin{array}{c}\text { Ekstrakt } \\
\text { konsantrasyonu } \\
(\% \mathrm{w} / \mathrm{w})\end{array}$} & \multicolumn{2}{c}{$\begin{array}{c}\text { Ergin Ölüm Oranı } \\
(\% \pm \text { standart hata) }\end{array}$} \\
\cline { 2 - 3 } & \multicolumn{2}{c}{ Maruz Brrakma Süresi } \\
\cline { 2 - 3 } & 24 saat & 48 saat \\
\hline 1.25 & $18.17 \pm 2.21$ & $30.18 \pm 1.56$ \\
\hline 2.5 & $32.72 \pm 1.98$ & $49.05 \pm 1.92$ \\
\hline 5 & $69.08 \pm 0.96$ & $86.79 \pm 0.98$ \\
\hline 10 & $89.09 \pm 2.08$ & $98.11 \pm 1.97$ \\
\hline 20 & $100 \pm 0.00$ & $100 \pm 0.00$ \\
\hline Kontrol & $0.00 \pm 0.00$ & $0.00 \pm 0.00$ \\
\hline
\end{tabular}

Zhang ve ark. (2008), Peygamber süpürgesi, Artemisia annua bitkisinin yapraklarından elde ettiği aseton ekstraktının T. urticae üzerindeki akarisidal etkisini araştırdığ $\breve{g}_{1}$ çlışmada, $5 \mathrm{mg} \mathrm{ml} \mathrm{m}^{-1}$ yaprak ekstraktı uygulamasindan 48 saat sonra \% 100 ölüm meydana geldiğini bildirmiştir. Erdoğan ve ark. (2012) yaptıkları çalışmada Allium sativum, Rhododendron luteum, Helichrysum arenarium, Veratrum album ve Tanacetum parthenium bitkilerinin ekstraktlarının $T$. urticae üzerindeki toksik etkisini araştırdıkları çalışmada $T$. parthenium ekstraktının (\% 12 'lik konsantrasyonu) en yüksek ölüme neden olduğunu bildirmiş̧lerdir. Diğer bir çalışmada, sarımsak ekstraktınin (Allium sativum) $50 \quad \mathrm{~g} \quad \mathrm{l}^{-1}$ konsantrasyonun, T. urticae erginlerinde uygulamadan üç gün sonra \%48; uygulamadan 6 gün sonra ise \% 57 ölüme neden olduğu bildirilmiştir (Dabrowsky ve Seredynska, 2007). Bu araştırmada özellikle \% 2.5 ve 5 konsantrasyonlarında her iki maruz bırakma süresinde ölüm oranlarının yükseldiği tespit edilmiştir.

Quercus coccifera Ekstraktının Plodia interpunctella Larvalarına Toksik Etkisi

Çizelge 3 incelendiğinde Quercus coccifera yaprak ekstraktının Plodia interpunctella larvalarma toksik etkisinin düşük olduğu görülmektedir. En yüksek konsantrasyonda bile (\% 20) 48 saat sonunda ancak \% 26 'llk bir ölüme neden olmuştur. Bouayad ve ark. (2013), Fas'ta geleneksel tıp alanında kullanılan 10 bitkinin methanol ekstraktlarını besinlerine karıştırarak $P$. interpunctella larvalarının gelişimine etkisini araştırmışlardır. Uygulamadan 8 gün sonra Kirmızı Kantaron, Centaurium erythraea ektraktının larva ağırlığında \% 33'e varan oranda bir düşüşe neden olduğunu, ayrıca Ajuga iva, Rosmarinus officinalis,
Centaurium erythraea ekstraktlarının besine karıştırıldığı bireylerde pupadan ergin çıkışının \% 2.5'in altında olduğunu bildirmişlerdir.

Çizelge 3. Quercus coccifera yaprak ekstraktının Plodia interpunctella larvasina toksik etkisi

\begin{tabular}{clc}
\hline \multirow{2}{*}{$\begin{array}{c}\text { Ekstrakt } \\
\text { konsantrasyonu } \\
(\% \mathrm{w} / \mathrm{w})\end{array}$} & \multicolumn{2}{c}{$\begin{array}{c}\text { Larva Ölüm Oranı } \\
(\% \pm \text { standart hata) }\end{array}$} \\
\cline { 2 - 3 } & \multicolumn{2}{c}{ Maruz Birakma Süresi } \\
\hline 10 & 24 saat & 48 saat \\
\hline 20 & $7.73 \pm 1.56$ & $14.99 \pm 3.86$ \\
\hline Kontrol & $20.74 \pm 2.48$ & $26.23 \pm 2.56$ \\
\hline & $0.00 \pm 0.00$ & $0.00 \pm 0.00$ \\
\hline
\end{tabular}

Zirai mücadelede sekonder metabolitlerin oldukça önemli yeri vardır (Aydın ve Mammadov, 2017). Çalışmada kullanılan Quercus coccifera bitkisinin odun ve kabuk kısmindan yapılan ekstraktlarda kermesoside, cocciferoside, (-)-8-chlorocatechin sekonder metabolitleri ve 3- hydroxy-1-(4-hydroxy-3methoxyphenyl)-propan-1-one ve 3 -hydroxy-1-(4hydroxy-3,5-dimethoxyphenyl)-propan-1-one, transresveratrol-3-O-glucopyranoside, lyoniresinol-9-Oxylopyranoside gibi fenolik bileşikleri tespit edilmiştir (Şöhretoğlu ve ark., 2014).

\section{SONUC}

Türkiye'de yeni bitkisel kökenli doğal insektisitlerin tespit edilmesi ve üretimi için bitki ekstrakt ve uçucu yağlarla ilgili çalışmaların sayısı gün geçtikçe artmaktadır. Son yıllarda özellikle Organik tarıma ve sürdürülebilir tarıma ilginin artmasıyla birlikte bu konudaki çalışmalar daha da yoğunluk kazanmıştır. $\mathrm{Bu}$ çalışmada Quercus coccifera yaprak ekstraktının $C$. maculatus ve $T$. urticae erginlerine değme (kontakt) toksisitesinin yüksek olduğu ancak $P$. interpunctella larvasına kontakt toksisitesinin düşük olduğu tespit edilmiştir. Quercus coccifera ekstraktı $C$. maculatus ve $T$. urticae erginlerinin kontrolünde ümitvar biyopestisit olarak değerlendirilme potansiyeli taşımaktadır. Özellikle tıp alanında son yıllarda Quercus coccifera ekstraktı üzerinde çalışmalar yapıldığı da dikkate alındığında (Anti kanser ve antimikrobiyal aktivite çalışmalarında) (Hayouni, 2007; Güneş ve ark. 2014; Şenol ve ark. 2018) tarımda da değerlendirilme potansiyeli taşıdığı göz önünde bulundurulmuştur.

\section{KAYNAKLAR}

Abbott WS 1925. A Method of Computing the Effectiveness of an Insecticide. Journal of Economic Entomology, 18: 265-267.

Altıkat A, Turan T, Ekmekyapar Torun F 2009. Türkiye'de Pestisit Kullanımı ve Çevreye Olan Etkileri. Atatürk Üniversitesi Ziraat Fakültesi Dergisi, 40 (2): 87-92. 
Avcı M 2005. Çeşitlilik ve Endemizm Açısından Türkiye'nin Bitki Örtüsü. Coğrafya Dergisi, 13: 2755.

Aydın Ç, Mammadov R 2017. Insektisit Aktivite Gösteren Bitkisel Sekonder Metabolitler ve Etki Mekanizması. Marmara Pharmaceutical Journal, 21: 30-37.

Bhaduri N, Ram S, Patil BD 1985. Evaluation of Some Plant Extract as Protectants Against Pulse Beetle, Callosobruchus maculatus F. Infesting Cowpea Seeds. Journal of Entomological Research, 9 (2): 183-187.

Bouayad N, Rharrabe K, Ghailani N, Jbilou R, Castañera P, Ortego F 2013. Insecticidal Effects of Moroccan Plant Extracts on Development, Energy Reserves and Enzymatic Activities of Plodia interpunctella. Spanish Journal of Agricultural Research, 11(1): 189-198.

Bulut E, Göçmen H 2000. Pests and Their Natural Enemies on Greenhouse Vegetables in Antalya. Integrated Control in Protected Crops Mediterranean Climate. IOBC/WPRS Bulletin, 23(1): 33-37.

Çetin H, Elma F 2017. Bazı Bitki Ekstraktlarının Börülce Tohum Böceği [Callosobruchus maculatus F. (Coleoptera: Chrysomelidae)] Erginlerine Etkileri. Harran Tarım ve Gıda Bilimleri Dergisi, 21(4): 404-411.

Dabrowsky ZT, Seredynska U 2007. Characterisation of the Two-spotted Spider Mite (Tetranychus urticae Koch: Tetranychidae) Responses to Aqueous Extracts from Selected Plant Species. Journal of Plant Protection Research, 47 (2): 114-123.

Dağlı F, Tunç I 2001. Dicofol Resistance in Tetranychus cinnabarinus Resistance and Stability of Resistance in Populations from Antalya Turkey. Pest Management Science, 57: 609-614.

Erdoğan P, Saltan G, Sever B 2010. Acı Biber (Capsicum annum L.) Ekstraktının iki noktalı kırmızı̈rümcek, Tetranychus urticae Koch (Arachnida: Tetranychidae)'ye Akarisit Etkisi. Bitki Koruma Bülteni, (50): 35-43.

Erdoğan P, Yıldırım A, Sever B 2012. Investigations on the Effects of Five Different Plant Extracts on the Two-Spotted Mite Tetranychus urticae Koch (Arachnida: Tetranychidae). Psyche, 1-5.

Güneş H, Oktay M, Çelebi F, Tül B 2014. Screening of Antimicrobial and Anticancer Potentials of Some Plant Extracts from Mugla Provience. Journal of Applied Biological Sciences, 8 (2): 16-21.

Hayouni EA, Abedrabba M, Bouix M, Hamdi M 2007. The Effects of Solvents and Extraction Method on the Phenolic Contents and Biological Activities In Vitro of Tunisian Quercus coccifera L. and Juniperus phoenicea L. Fruit Extracts. Food Chemistry, 105: 1126-1134.

Johnson JA, Wofford PL, Whitehand LC 1992. Effect of Diet and Temperature on Development Rates,
Survival, and Reproduction of the Indianmeal Moth (Lepidoptera: Pyralidae). J. Econ. Entomol. 85: 561566.

Kamaraj C, Abdul Rahuman A, Bagavan A 2008. Screening for Antifeedant and Larvicidal Activity of Plant Extracts Against Helicoverpa armigera (Hübner), Sylepta derogata (F.) and Anopheles stephensi (Liston). Parasitol Research, 103: 13611368.

Karakaş M 2017. Use of Aromatic Plant Extracts as Bio-insecticides for the Control of Stored-Product Insect, Sitophilus granarius. International Journal of Entomology Research, 2 (1): 27-29.

Louise KM, Habiba K, Sidonie FT, Tchuenguem Fohouo FN 2018. Management of Callosobruchus maculatus F. (Coleoptera: Bruchidae) Using Methanol Extracts of Carica papaya, Carissa edulis, Securidaca longepedonculata and Vinca rosea and Impact of Insect Pollinators on Cowpea Types in the Far-North Region of Cameroon. Journal of Entomology and Zoology Studies, 6(2): 1017-1027.

Nansen C, Phillips, TW, Parajulee MN, FranquiRivera RA 2004. Comparison of Direct and Indirect Sampling Procedures Plodia interpunctella in a Corn Storage Facility. J. Stored Prod. Res., 40: 151168.

Öncüer C 2000.Tarımsal Zararlılarla Savaş Yöntem ve İlaçları. Adnan Menderes Üniversitesi Yayınları, $333 \mathrm{Sy}$.

Shiberu T, Getu A 2017. Effects of Crude Extracts of Medicinal Plants in the Management of Tuta absoluta (Meyrick) (Lepidoptera: Gelechiidae) Under Laboratory and Glasshouse Conditions in Ethiopia. Journal of Entomology and Nematology, 9(2): 9-13.

Şenol FZ, Şekeroğlu N, Gezici S, Kılıç E, Erdoğan Orhan I 2018. Neuroprotective Potential of the Fruit (Acorn) from Quercus coccifera L.. Turkish Journal of Agriculture and Forestry, 42: 82-87.

Şöhretoğlu D, Kuruüzüm-Uz A, Simon A, Patócs T, Dékány M 2014. New Secondary Metabolites from Quercus coccifera L.. Records Natural Products, 8(4): 323-329.

Taş MN, Uysal M, Çetin H 2015. Bazı Bitki Ekstraktlarının Callosobruchus maculatus (F.) (Col.: Bruchidae)' e Olan Kontak Toksisiteleri, Bitki Koruma Bülteni, 55(3): 195-205.

Tiryaki O, Canhilal R, Horuz S 2012. Tarım İlaçları Kullanımı ve Riskleri. Erciyes Üniversitesi Fen Bilimleri Enstitüsü Dergisi, 26(2): 154-169.

Tavares WS, Cruz I, Petacci F, Assis Júnior SL, Sousa Freitas S, Zanuncio JC, Serrão JE 2009. Potential Use of Asteraceae Extracts to Control Spodoptera frugiperda (Lepidoptera: Noctuidae) and Selectivity to Their Parasitoids Trichogramma pretiosum (Hymenoptera: Trichogrammatidae) and Telenomus remus (Hymenoptera: Scelionidae). 
Industrial Crops and Products, 30: 384-388.

Yanar D, Düzdemir O 2012. Bazı Bitki Ekstraktlarının ve Bitkisel Preparatların Fasulye Tohum Böceğine (Acanthoscelides obtectus (Say.)) Olan Etkisi. Tarım Bilimleri Araştırma Dergisi, 6 (1): 36-40.

Yaşar S, Beram A, Güler G 2017. Kermes Meşesi (Quercus coccifera L.) Odunu Fenolik Ekstraktifleri. Mehmet Akif Ersoy Üniversitesi Fen Bilimleri Enstitüsü Dergisi 1 (Özel Sayı) : 73-78.
Yıldırım E 2008. Tarımsal Zararlılarla Mücadele Yöntemleri ve Kullanılan İlaçlar. Atatürk Üniversitesi Ziraat Fak. Yayınları, Yayın No:219, Erzurum, 350s.

Zhang Y, Ding W, Zhao Z, Wu Jing, Fan Yu-hu 2008. Studies on Acaricidal Bioactivities of Artemisia annua L. Extracts Against Tetranychus cinnabarinus Boisd (Acari: Tetranychidae). Agricultural Sciences in China, 7(5): 577-584. 